\title{
TP53 genetic alterations in Arab breast cancer patients: Novel mutations, pattern and distribution
}

\author{
ABEER J. AL-QASEM ${ }^{1}$, MOHAMED TOULIMAT ${ }^{2}$, ABDELMONEIM M. ELDALI $^{3}$, \\ ASMA TULBAH ${ }^{2}$, NUJOUD AL-YOUSEF ${ }^{1}$, SOOAD K. AL-DAIHAN ${ }^{4}$, \\ NADA AL-TASSAN ${ }^{5}$, TAHER AL-TWEIGERI ${ }^{6}$ and ABDELILAH ABOUSSEKHRA ${ }^{1}$ \\ Departments of ${ }^{1}$ Biological and Medical Research, ${ }^{2}$ Pathology, ${ }^{3}$ Biostatistics, Epidemiology and Scientific \\ Computing, and ${ }^{4}$ Genetics; ${ }^{5}$ Oncology Center, King Faisal Specialist Hospital and Research Center; \\ ${ }^{6}$ Department of Biochemistry, King Saud University, Riyadh, Saudi Arabia
}

Received October 7, 2010; Accepted January 3, 2011

DOI: $10.3892 / \mathrm{ol} .2011 .236$

\begin{abstract}
Breast cancer remains a worldwide public health concern. The incidence and mortality of breast cancer varies significantly in ethnically and geographically distinct populations. In the Kingdom of Saudi Arabia (KSA) breast cancer has shown an increase in incidence and is characterized by early onset and aggressiveness. The tumor suppressor TP53 gene is a crucial genetic factor that plays a significant role in breast carcinogenesis. Furthermore, studies have shown a correlation between certain p53 mutations and response to therapy in breast cancer. In the present study, TP53 mutations were identified by direct sequencing of the gene (exons 4-9) from 119 breast cancer tissues. The prevalence of TP53 mutations in Arab breast cancer patients living in the KSA is among the highest in the world (40\%). Notably, $73 \%$ of the patients whose tumors harbored p53 mutations were less than 50 years of age. Furthermore, for the first time, we identified 7 novel mutations and 16 mutations in breast cancer tissues. Notably, all the novel point mutations were found in exon 4, wherein $29 \%$ of the mutations were localized. Furthermore, an excess of $\mathrm{G}: \mathrm{C} \rightarrow \mathrm{A}: \mathrm{T}$ transitions (49\%) at non-CpG sites was noted, suggesting exposure to particular environmental carcinogens such as N-nitroso compounds. The results indicate that the TP53 gene plays a significant role in breast carcinogenesis and the early onset of the disease among Arab female individuals.
\end{abstract}

\section{Introduction}

Breast cancer has a major impact on the health of women worldwide. It is the most frequently diagnosed cancer and

Correspondence to: Dr Abdelilah Aboussekhra, Department of Biological and Medical Research, King Faisal Specialist Hospital and Research Center BMR, MBC \# 03-66, P.O. Box 3354, Riyadh 11211, Saudi Arabia

E-mail: aboussekhra@kfshrc.edu.sa

Key words: TP53, breast cancer risk, early onset, mutations a leading cause of cancer-related death, ranking second in Caucasian (1) and Saudi female patients (Cancer Incidence Report, NCR, 2004). The incidence and mortality rates vary between various ethnically and geographically distinct populations, with the lowest incidence reported among Asians and the highest among North Americans (2). Multiple causes characterize breast carcinomas, which may be either familial or sporadic. Genetic predisposition accounts for only about $5-10 \%$ of breast cancer, whereas $90 \%$ of breast cancer cases are sporadic and their origin remains to be determined (3). The Saudi population comprises more than $50 \%$ of females younger than 20 years old. In this population, the majority of breast cancer cases diagnosed are at advanced stages and at an early age (4). Similar characteristics have been found in African-American female individuals $(5,6)$.

Breast carcinogenesis is associated with various types of somatic genetic alterations, such as mutations in oncogenes and tumor suppressor genes (7). The most frequently mutated gene in human malignancies, including breast cancer, is the TP53 gene (8). This important tumor suppressor gene is a multifunctional transcription factor involved in the control of cell cycle progression, DNA repair, apoptosis and angiogenesis (9). The proportion of TP53 mutations in various cancer tissues ranges from 10 to $80 \%$ (10), while that of TP53 mutations reported in breast tumors ranges from 15 to $71 \%$, with significant differences among populations. Over 1,400 TP53 mutations have been identified in breast cancer (11). Of these mutations, $80 \%$ are clustered within exons 5-8 (12). Notably, the proportion of TP53 mutations is higher in younger patients and those with advanced breast cancer (13); these patients comprise the prevalent breast cancer patient group among the Saudis. Furthermore, variations in patterns and distribution of p53 mutations in breast cancer occur according to ethnicity and geographical location, indicating the effect of genetic and environmental factors (14).

Cells lacking normal p53 function have a selective growth advantage and are more resistant to ionizing radiation and frequently used anticancer drugs compared to cells with wild-type p53 protein (15). TP53 gene mutations predict the response of breast cancer patients to treatment with various 
Table I. TP53 primers used in the PCR reactions.

\begin{tabular}{|c|c|c|c|c|c|}
\hline Primer & Length (bp) & Sequence (5' to $\left.3^{\prime}\right)$ & Size & Annealing temperature $\left({ }^{\circ} \mathrm{C}\right)$ & $\mathrm{MgCl}_{2}(\mathrm{mM})$ \\
\hline Exon 4 & & & 370 & 62 & 1.5 \\
\hline Forward & 20 & TGA GGA CCT GGT CCT CTG AC & & & \\
\hline Reverse & 20 & CGG CCA GGC ATT GAA GTC TC & & & \\
\hline Exon 5 & & & 330 & 62 & 3.0 \\
\hline Forward & 20 & TGT TCC AGT TGC TTT ATC TG & & & \\
\hline Reverse & 20 & AGA GCA ATC AGT GAG GAA TC & & & \\
\hline Exon 6 & & & 180 & $56-62$ & 2.0 \\
\hline Forward & 20 & GGC CTC TGA TTC CTC ACT GA & & & \\
\hline Reverse & 20 & GGT CCC CTA AGC AGC AGG AG & & & \\
\hline Exon 7 & & & 257 & 62 & 2.5 \\
\hline Forward & 20 & CAG GTC TCC CCA AGG CGC AC & & & \\
\hline Reverse & 20 & TGG AAG AAA TCG GTA AGA GG & & & \\
\hline Exon 8,9 & & & 391 & $56-62$ & 2.5 \\
\hline Forward & 20 & CCT TAC TGC CTC TTG CTT CT & & & \\
\hline Reverse & 20 & TGT TAG ACT GGA AAC TTT CC & & & \\
\hline
\end{tabular}

chemotherapeutic agents $(16,17)$. Furthermore, it has been shown that the TP53 mutation status is a crucial survival marker of breast cancer that may provide prognostic data which complements clinical variables (18).

In the present study, the prevalence of TP53 mutations in Arab breast cancer patients was among the highest in the world (40\%), and occurred more frequently in young patients. Notably, 7 novel mutations, including a 15-bp deletion, were identified in these sporadic breast cancer patients.

\section{Materials and methods}

Sample collection. A total of 119 archived breast tumor samples were collected from Arab patients living in Saudi Arabia and suffering invasive ductal carcinoma. All of these patients were diagnosed at King Faisal Specialist Hospital and Research Center in Riyadh. The experimental protocol was approved by the institutional Basic Research and Ethics Protocol Committees (RAC proposal no. 2040037). The age of the patients at the time of diagnosis ranged from 22 to 80 years (median 51). A total of 108 fresh blood samples $(5 \mathrm{ml})$ were collected from volunteer healthy Arab female individuals, and used as controls. The age of the healthy Saudi female individuals (controls) ranged from 17 to 76 years (median 47).

DNA purification. Genomic DNA was purified using the Gentra Puregen kit according to the manufacturer's instructions (Gentra Puregene Blood kit; Qiagen, Valencia, CA, USA; cat. no D-50K1-4).

DNA amplification and sequencing of the TP53 gene. Standard PCR was performed to amplify exons 4-9 and their intron/ exon borders of the TP53 gene, using the HotStar Taq polymerase kit (Qiagen, Chatsworth, CA, USA). The primers used for this amplification are listed in Table I. Each PCR reaction was performed in a total volume of $25 \mu$ l containing
$4 \mathrm{ng}$ of genomic DNA, $0.5 \mathrm{mM}$ dNTPs, $1 \mathrm{mM}$ primers, 0.04 units Taq DNA polymerase and $\mathrm{MgCl}_{2}$ (1.5-3 mM). $\mathrm{MgCl}_{2}$ concentrations were optimized according to the different primers (Table I). Following a denaturation step of $10 \mathrm{~min}$ at $94^{\circ} \mathrm{C}$, the PCR amplification consisted of 35 cycles of $45 \mathrm{sec}$ at $94^{\circ} \mathrm{C}, 45 \mathrm{sec}$ at $62^{\circ} \mathrm{C}, 45 \mathrm{sec}$ at $72^{\circ} \mathrm{C}$, followed by a final extension step of $10 \mathrm{~min}$ at $72^{\circ} \mathrm{C}$. The PCR products were then directly sequenced using the ABI PRISM BigDye Terminator v3.1 cycle sequencing kit (Applied Biosystems, Foster City, CA, USA). The unincorporated dye labeled terminators were removed using the DyeEx 96 kit (Qiagen). The reaction product was resuspended in a formamide loading buffer, and then separated and detected in the ABI 3730x1 DNA analyzer (Applied Biosystems). The analysis of the obtained sequence was carried out using the GeneBank database, NT_010718. TP53 somatic mutations were confirmed by two independent experiments.

Statistical analysis. Statistical analysis was carried out using the SPSS program version 17. The Chi-square test $\left(\chi^{2}\right)$ was used to test for an association between categorical data. $\mathrm{P} \leq 0.05$ was considered to be statistically significant.

\section{Results}

Prevalence of TP53 mutations is high among Arab breast cancer patients. Screening for TP53 mutations was carried out on exons 4-9.

DNA from 119 breast carcinoma tumor samples was amplified and sequenced. A total of 40 of 119 (33.61\%) patients harbored mutations in the TP53 gene; with 6 patients harboring more than one mutation. Subsequently, 47 substitutions were identified in the samples obtained from these 40 patients. Notably, only 19 exonic mutations of these substitutions were previously identified in breast cancer patients (Table II). Different types of mutations were detected: $28(59.57 \%)$ were missense mutations, $6(12.77 \%)$ were silent, $5(10.64 \%)$ were nonsense 
Table II. Summary of TP53 mutations and their nature/location found in breast cancer tissues.

\begin{tabular}{|c|c|c|c|c|c|}
\hline Base change & $\begin{array}{l}\text { Structural } \\
\text { change }\end{array}$ & Mutation type & $\begin{array}{l}\text { Exon/ } \\
\text { Intron }\end{array}$ & $\begin{array}{c}\text { Coding } \\
\text { Description }\end{array}$ & $\begin{array}{l}\text { Mut } \\
\text { - ID }\end{array}$ \\
\hline $\mathrm{GAC}>\mathrm{GGC}^{\mathrm{a}}$ & $\mathrm{D} 48 \mathrm{G}$ & Transition & E4 & c. $143 \mathrm{~A}>\mathrm{G}$ & 449 \\
\hline $\mathrm{TGG}>\mathrm{TAG}^{\mathrm{a}}$ & W53X & Transition & E4 & c. $158 \mathrm{G}>\mathrm{A}$ & 502 \\
\hline $\mathrm{ACT}>\mathrm{CCT}^{\mathrm{c}}$ & T55P & Transversion & E4 & c. $163 \mathrm{~A}>\mathrm{C}$ & - \\
\hline $\mathrm{CCA}>\mathrm{CTA}^{\mathrm{c}}$ & P58S & Transition & E4 & c. $173 \mathrm{C}>\mathrm{T}$ & - \\
\hline $\mathrm{CCC}>\mathrm{CCT}^{\mathrm{c}}$ & P64L & Transition & E4 & c. $192 \mathrm{C}>\mathrm{T}$ & - \\
\hline $\mathrm{GCA}>\mathrm{GGA}^{\mathrm{a}}$ & A76G & Transversion & E4 & c. $227 \mathrm{C}>\mathrm{G}$ & 753 \\
\hline $\mathrm{GCA}>\mathrm{GCG}^{\mathrm{c}}$ & A78A & Transition & E4 & c. $234 \mathrm{~A}>\mathrm{G}$ & - \\
\hline $\mathrm{GCC}>\mathrm{GCT}^{\mathrm{a}}$ & A84A & Transition & $\mathrm{E} 4$ & c. $252 \mathrm{C}>\mathrm{T}$ & 843 \\
\hline Del of $\mathrm{C}^{\mathrm{a}}$ & A88TdelfsX33 & Deletion & E4 & c.263del1 & 887 \\
\hline $\mathrm{CCC}>\mathrm{CCT}^{\mathrm{a}}$ & P89P & Transition & E4 & c. $267 \mathrm{C}>\mathrm{T}$ & 899 \\
\hline $\mathrm{TAC}>\mathrm{TCC}^{\mathrm{c}}$ & Y107S & Transversion & E4 & c. $320 \mathrm{~A}>\mathrm{C}$ & - \\
\hline $\mathrm{GGG}>\mathrm{AGG}^{\mathrm{a}}$ & G117R & Transition & E4 & c.349G >A & 1209 \\
\hline $\mathrm{C}>\mathrm{T}$ & No change & Transition & IVS 4-3 & c. $376-3 \mathrm{C}>\mathrm{T}$ & 5820 \\
\hline $\mathrm{C}>\mathrm{T}$ & - & Transition & IVS 4-14 & c. $376-14 \mathrm{C}>\mathrm{T}$ & - \\
\hline $\mathrm{TCC}>\mathrm{TTC}^{\mathrm{b}}$ & S127F & Transition & E5 & c. $380 \mathrm{C}>\mathrm{T}$ & 1341 \\
\hline Del CAA $^{c}$ & L130-N131delLfsX15 & Deletion & E5 & c. $390-392 \mathrm{del} 3$ & - \\
\hline $\mathrm{GTG}>\mathrm{GCG}^{\mathrm{b}}$ & $\mathrm{V} 143 \mathrm{~A}$ & Transition & E5 & c. $428 \mathrm{~T}>\mathrm{C}$ & 1590 \\
\hline $\mathrm{CCC}>\mathrm{CCT}^{\mathrm{b}}$ & P153P & Transition & E5 & c. $459 \mathrm{C}>\mathrm{T}$ & 1761 \\
\hline $\mathrm{ACC}>\mathrm{ATC}^{\mathrm{b}}$ & $\mathrm{T} 155 \mathrm{I}$ & Transition & E5 & c. $464 \mathrm{C}>\mathrm{T}$ & 1794 \\
\hline $\mathrm{ACC}>\mathrm{ACT}^{\mathrm{b}}$ & $\mathrm{T} 155 \mathrm{~T}$ & Transition & E5 & c. $465 \mathrm{C}>\mathrm{T}$ & 1799 \\
\hline $\mathrm{ACC}>\mathrm{AAC}^{\mathrm{a}}$ & $\mathrm{T} 155 \mathrm{~N}$ & Transversion & E5 & c. $464 C>A$ & 1792 \\
\hline Del $15 b^{c}$ & V157-A161del & Deletion & E5 & c. $469-483$ del 15 & - \\
\hline $\mathrm{ATC}>\mathrm{ATT}^{\mathrm{b}}$ & I162I & Transition & E5 & c. $486 \mathrm{C}>\mathrm{T}$ & 1932 \\
\hline $\mathrm{CAG}>\mathrm{TAG}^{\mathrm{b}, \mathrm{d}}$ & Q165X & Transition & E5 & c. $493 \mathrm{C}>\mathrm{T}$ & 1972 \\
\hline $\mathrm{TGC} \mathrm{TAC}^{\mathrm{b}}$ & $\mathrm{C} 176 \mathrm{Y}$ & Transition & E5 & c. $527 \mathrm{G}>\mathrm{A}$ & 2166 \\
\hline $\mathrm{CAT}>\mathrm{CGT}^{\mathrm{b}}$ & H193R & Transition & E6 & c. $578 \mathrm{~A}>\mathrm{G}$ & 2410 \\
\hline $\mathrm{CAT}>\mathrm{TAT}^{\mathrm{b}}$ & H193Y & Transition & E6 & c. $577 \mathrm{C}>\mathrm{T}$ & 2408 \\
\hline TAT $>$ GAT $^{\mathrm{a}}$ & Y220D & Transversion & E6 & c. $658 \mathrm{~T}>\mathrm{G}$ & 2819 \\
\hline $\mathrm{TAT}>\mathrm{TGT}^{\mathrm{b}}$ & $\mathrm{T} 220 \mathrm{C}$ & Transition & E6 & c. $659 \mathrm{~A}>\mathrm{G}$ & 2821 \\
\hline $\mathrm{GAG}>\mathrm{GCG}^{\mathrm{a}, \mathrm{d}}$ & E221D & Transversion & E6 & c. $662 \mathrm{~A}>\mathrm{C}$ & 2833 \\
\hline TAC $>\mathrm{TAG}^{\mathrm{b}, \mathrm{d}}$ & Y234X & Transversion & E7 & c. $702 \mathrm{C}>\mathrm{G}$ & 3029 \\
\hline $\mathrm{TAC}>\mathrm{AAC}^{\mathrm{b}}$ & Y234N & Transversion & E7 & c. $700 \mathrm{~T}>\mathrm{A}$ & 3020 \\
\hline $\mathrm{TGT}>\mathrm{TTT}^{\mathrm{b}}$ & $\mathrm{C} 238 \mathrm{~F}$ & Transversion & E7 & c. $713 \mathrm{G}>\mathrm{T}$ & 3108 \\
\hline $\mathrm{C}>\mathrm{T}$ & - & Transition & IVS 7-15 & c. $783-15 \mathrm{C}>\mathrm{T}$ & - \\
\hline GTG $>\mathrm{TTG}^{\mathrm{b}}$ & V272L & Transversion & $\mathrm{E} 8,9$ & c. $814 \mathrm{G}>\mathrm{T}$ & 3713 \\
\hline $\mathrm{AGA}>\mathrm{GGA}^{\mathrm{b}}$ & R280G & Transition & $\mathrm{E} 8,9$ & c. $838 \mathrm{~A}>\mathrm{G}$ & 3844 \\
\hline $\mathrm{AGA}>\mathrm{ACA}^{\mathrm{a}}$ & $\mathrm{R} 280 \mathrm{~T}$ & Transversion & $\mathrm{E} 8,9$ & c. $839 \mathrm{G}>\mathrm{C}$ & 3850 \\
\hline $\mathrm{CCT}>\mathrm{CTT}^{\mathrm{b}}$ & P295L & Transition & $\mathrm{E} 8,9$ & c. $884 C>T$ & 4084 \\
\hline $\mathrm{CAC}>\mathrm{TAC}^{\mathrm{a}}$ & H297Y & Transition & $\mathrm{E} 8,9$ & c. $889 \mathrm{C}>\mathrm{T}$ & 4106 \\
\hline $\mathrm{CCC}>\mathrm{CTC}^{\mathrm{a}}$ & P316L & Transition & $\mathrm{E} 8,9$ & c. $947 \mathrm{C}>\mathrm{T}$ & 4348 \\
\hline $\mathrm{CAG}>\mathrm{CGG}^{\mathrm{a}}$ & Q317R & Transition & $\mathrm{E} 8,9$ & c. $950 \mathrm{~A}>\mathrm{G}$ & 4363 \\
\hline ACC $>$ ATC $^{a}$ & T329I & Transition & $\mathrm{E} 8,9$ & c.986C>T & 4501 \\
\hline $\mathrm{G}>\mathrm{A}$ & - & Transition & IVS $8+18$ & c. $919+18 \mathrm{G}>\mathrm{A}$ & - \\
\hline $\mathrm{G}>\mathrm{A}$ & - & Transition & IVS 9+28 & c. $993+28 \mathrm{G}>\mathrm{A}$ & - \\
\hline
\end{tabular}

Mut, mutations. ${ }^{a}$ Mutations reported in cancers other than breast cancer. ${ }^{\mathrm{b}}$ Mutations reported in breast cancer. ${ }^{\mathrm{c}}$ Mutations not previously reported. ${ }^{\mathrm{d}}$ TP53 mutations reported more than once. International Agency for Research on Cancer database, TP53 genetic variation in human cancer, IARC release R13 (2008), used as a reference. 
A

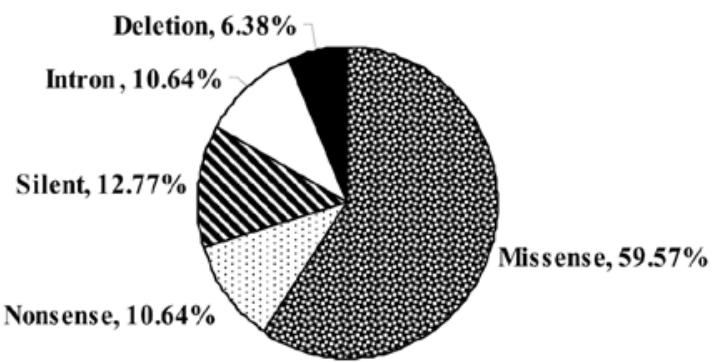

B Transversion,

$29.50 \%$

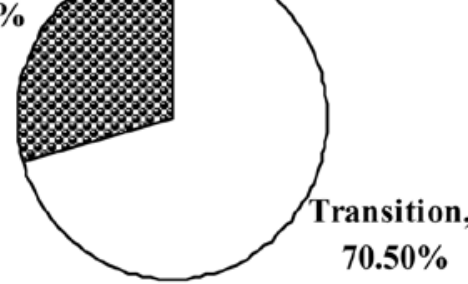

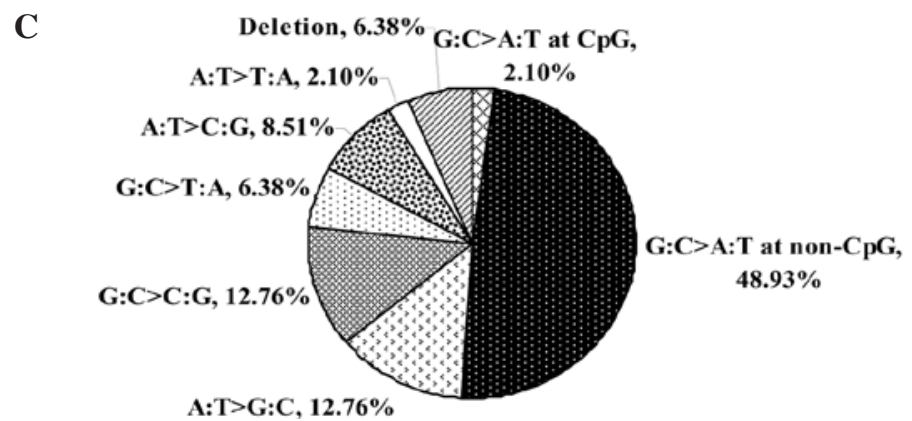

Figure 1. Types and proportions of the different TP53 mutations identified in the present study. TP53 mutation patterns are shown as pie charts indicating the proportions of the different types of mutations.

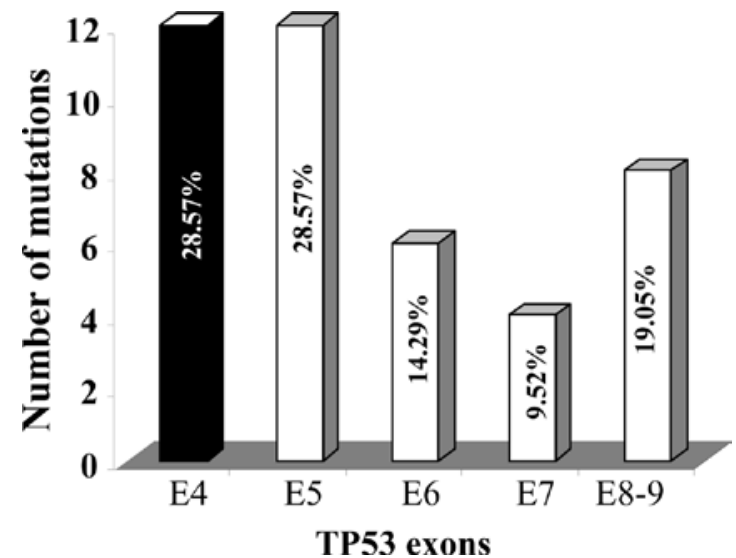

Figure 2. Exon distribution of TP53 mutations identified in breast cancer patients from Saudi Arabia. The numbers within the columns indicate the proportions of mutations in the different exons $(\mathrm{E} 4$ to $E 8,9)$ of the gene.

(stop) mutations, and $3(6.38 \%)$ deletions and 5 mutations (10.64\%) were found in the intron-exon intersections (Fig. 1A). Two of the 3 deletions led to a premature stop codon (frame shift) (Table II).

The majority of the identified mutations were transitions (Fig. 1B). Only one transition mutation of proline-153 occurred at a $\mathrm{CpG}$ site. Furthermore, various base changes were identified in the 47 TP53 mutations with 24 (51.1\%) C:G $\rightarrow \mathrm{T}: \mathrm{A}$ transitions (at the $\mathrm{CpG}$ and non-CpG sites) representing the most frequent one (Fig. 1C). The frequency of this transition reached $48.93 \%$ at the non-CpG sites (Fig. 1C).

Fig. 2 shows the distribution of the TP53 mutations within exons 4-9 of the gene. The majority of the mutations were identified in exons 4 and 5 (12 mutations, representing 29\%, in each). However, only 4 mutations were identified in exon 7 , while exons 6 and 8,9 harbored 6 and 8 mutations, respectively. This finding shows that exon 4 is a hot-spot for TP53 mutations in the Saudi Arabian population. Furthermore, 9 of the 47 mutations were found within the conserved regions (II, III, IV and V) of the TP53 gene. Of the 9 mutations, 3 were identified in conserved region $\mathrm{V}$ at valine 272 and argenine 280 (Table II). Argenine 280 is a significant amino acid involved in direct DNA binding. Another 2 mutations were found at cysteine 176 and 238, in conserved regions III and IV, respectively. These cysteines are also directly involved in the binding of the zinc molecule (Table II). Six (12.8\%) mutations were identified within the zinc-binding loop domains L2 and L3 (codons 163-195 and 236-251, respectively) (Table II). No mutation was detected at the 3 hot-spot codons 248,273 and 175 , nor at the highly mutagenic codons 245,249 and 282 (14). Furthermore, only one mutation was identified at codon 176 and 2 at codon 220.

Identification of novel mutations in the TP53 gene. In the present study, 16 new mutations were identified in the TP53 gene. These mutations were found in 14 different patients. One of these patients harbored 3 mutations. The majority of these mutations were transitional (10 transitions vs. 6 transversions) (Table II). In addition, 7 novel changes were identified in the TP53 gene (not previously reported in breast cancer or any other tumor type, IARC database, 2008). These changes (5 base substitutions and 2 deletions) were found in 6 different patients, since the tumor from one patient had 2 of these novel mutations at codons 58 and 64 (Table II). All of the 5 base substitutions were located in exon 4 at codons 58, 64, 55, 78 and 107 (3 transitions 
Table III. Association of TP53 gene mutations with the clinicopathological characteristics of Arab breast cancer patients.

\begin{tabular}{|c|c|c|c|c|}
\hline & Total (n) & Positive n (\%) & Negative n (\%) & P-value \\
\hline \multicolumn{5}{|l|}{ Age } \\
\hline$<50$ & 69 & $24 \quad(34.8)$ & $45 \quad(65.2)$ & \multirow[t]{2}{*}{0.4480} \\
\hline$\geq 50$ & 33 & $9(27.3)$ & $24(72.0)$ & \\
\hline \multicolumn{5}{|l|}{ Menopausal status } \\
\hline Premenopausal & 68 & $24(23.08)$ & $44(42.31)$ & \multirow[t]{2}{*}{0.1690} \\
\hline Postmenopausal & 36 & $8(7.69)$ & $28(26.92)$ & \\
\hline \multicolumn{5}{|l|}{ ER status } \\
\hline Positive & 48 & $13(18.31)$ & $35(49.30)$ & \multirow[t]{2}{*}{0.7690} \\
\hline Negative & 23 & 7 (9.86) & $16(22.54)$ & \\
\hline \multicolumn{5}{|l|}{ PR status } \\
\hline Positive & 1 & $0 \quad(0.00)$ & 1 (7.69) & \multirow[t]{2}{*}{0.7640} \\
\hline Negative & 12 & $1 \quad(7.69)$ & $11(84.62)$ & \\
\hline \multicolumn{5}{|l|}{ ErbB2 status } \\
\hline Positive & 45 & $18(17.48)$ & $27(26.21)$ & \multirow[t]{2}{*}{0.0850} \\
\hline Negative & 58 & $14(13.59)$ & $44(42.72)$ & \\
\hline \multicolumn{5}{|c|}{ Involvement of lymph nodes } \\
\hline Positive & 46 & $16(17.20)$ & $30(32.26)$ & \multirow[t]{2}{*}{0.4590} \\
\hline Negative & 47 & $13(13.98)$ & $34(36.56)$ & \\
\hline \multicolumn{5}{|c|}{ Clinical stage of tumors } \\
\hline I & 16 & 3 (3.19) & $13(13.83)$ & \multirow{4}{*}{0.0447} \\
\hline II & 35 & $11(11.70)$ & $24(25.53)$ & \\
\hline III & 22 & $12(12.77)$ & $10(10.64)$ & \\
\hline IV & 21 & $4 \quad(4.26)$ & $17(18 / 09)$ & \\
\hline \multicolumn{5}{|c|}{ Histopathological grade of tumors } \\
\hline I & 9 & $3(2.88)$ & $6(5.77)$ & \multirow{3}{*}{0.6120} \\
\hline II & 53 & $14(13.46)$ & $39(37.50)$ & \\
\hline III & 42 & $15(14.42)$ & $27(25.96)$ & \\
\hline
\end{tabular}

and 2 transversions) (Table II). The 2 novel deletions of 3 and $15 \mathrm{bp}$ were identified in exon 5 (Table II). The second deletion did not lead to a premature stop codon, whereas the first one did following the addition of 15 new amino acids.

The frequency of the 7 novel changes was $<1 \%$. Therefore, they were considered as mutations. To verify this, we sequenced exon 4 which encompassed the 5 base substitutions from 108 DNA blood samples from healthy Arab female controls. No substitutions were identified at these sites, confirming that the substitutions identified in the breast cancer tissues were novel mutations. Therefore, the frequency of p53 mutations in the Arab breast cancer patients was $39.49 \%$.

Association between TP53 mutations and the age of Arab breast cancer patients. The potential link between TP53 mutations and the age of breast cancer patients was investigated. The patients were divided into two subgroups depending on their age; the first group included patients younger than 50 years of age (young patients), and the second included patients of 50 years or older ('old' patients). As expected, most of the Arab breast cancer patients (68\%) were under 50 years of age, confirming the early onset of breast cancer in this population. Notably, among 33 patients that harbored TP53 mutations in their tumors, 24 (73\%) were young patients, whereas only 9 (27\%) were considered older patients. In each subgroup, patients with tumors harboring TP53 mutations were compared with those patients with tumors without TP53 mutations. Table III shows that the TP53 gene mutations were more frequent in tumors from younger patients with a prevalence of $35 \%$, whereas in the older patients the TP53 mutations were only $27 \%$. However, the difference was not statistically significant $(\mathrm{p}=0.45)$.

Association between TP53 mutations and the clinocopathological characteristics of Arab breast cancer patients. To investigate the potential role of p53 in the development and progression of primary breast tumors, the clinicopathological characteristics of the patients with tumors harboring p53 mutations were compared with those of patients that had tumors without p53 mutations. A statistically significant correlation between the presence of p53 mutations and the clinical stage of the tumors was found $(p=0.0447)$. Patients with locally advanced breast cancer stage III $\mathrm{A}+\mathrm{B}$ showed the highest proportion of p53 mutations. On the other hand, no statistically significant correlation was found with the other characteristics, such as the menopausal status, the histopathological grade, the presence or absence of lymphatic or vascular invasion, ER/PR status and Her2neu. 


\section{Discussion}

In the present study, the frequency of TP53 mutations in Arab breast cancer patients living in Saudi Arabia was found to be $39.49 \%$. This frequency is considered to be relatively high, since it is significantly higher than the previously reported mean proportion of $25 \%$ (range $15-71 \%$; examined in 1425 breast tumor samples worldwide) (19). It is also higher than the prevalence of p53 mutations in breast tumors determined in a meta-analysis (18\%) (20) and in the IARC mutation prevalence database on all breast cancers, $\mathrm{R} 9$ release (28\%) (21). Therefore, the frequency of TP53 mutations in the KSA is one of the highest in the world. It is similar to the frequency found in Kashmir (44\%) (22), the USA (45\%) (21), Japan (47.5\%) (21), the UK (34.5\%) (21), and in African-Americans (34.5\%) (23). However, it is higher than the prevalence reported in patients from Delhi, India (3\%) (24), France (19\%) (25), Tokyo (25\%) (26) and US midwestern Caucasians (30\%) (27). This variation in p53 mutations in breast cancers may be due to factors such as the ethno-geographically diverse populations studied, exposure to various carcinogens, size of the studied population, life-style and dietary habits. Notably, 7 novel mutations (not previously reported in the TP53 gene) were identified during this study; 5 of the 7 mutations were found in exon 4 . Therefore, tumors from Arab breast cancer patients have a high prevalence (28.57\%) of TP53 mutations in exons 4 and 5 , whereas the smallest proportion of TP53 mutations $(9.52 \%)$ was found in exon 7. However, in the IARC database, exon 5 has the highest proportion of TP53 mutations in breast cancer (30.6\%) followed by exon 7 (23.5\%), while exon 4 represents only $4.2 \%$ of mutations (IARC TP53 Database, R14 release, November 2009, http://www.iarc.fr/p53/homepage.htm/). Therefore, even the distribution of TP53 mutations in the various exons of the gene appears to be population-dependent. Brazilian women of African descent have a higher proportion of mutations in exons 5 and 7, whereas Brazilian women of Caucasian descent have more mutations in exon 8 . No mutations were found in Brazilian patients of African descent in exon 4 (29). In the Kashmiri population, no mutation was found in exon 5, and $52.9 \%$ of mutations were identified in exon 6 (22). To the best of our knowledge, this study is the first to report a high proportion of mutations in exon 4 of the TP53 gene.

When we compared the TP53 mutational pattern in the Arab breast cancer population to the patterns of 15 other populations from low and high breast cancer-risk countries, we found that the Saudi population is characterized by a low frequency (2.1\%) of the $\mathrm{G}: \mathrm{C} \rightarrow \mathrm{A}: \mathrm{T}$ transition (at $\mathrm{CpG}$ sites) and a high frequency $(48.9 \%)$ of the mutational type $\mathrm{G}: \mathrm{C} \rightarrow \mathrm{A}: \mathrm{T}$ transition (at non-CpG sites). Thus, the Arab population living in Saudi Arabia possesses the second highest frequency of $\mathrm{G}: \mathrm{C} \rightarrow \mathrm{A}: \mathrm{T}$ transitions at non- $\mathrm{CpG}$ sites after a New Orleans population of African or Caucasian descent (57\%) (23). On the other hand, the frequency of $\mathrm{G}: \mathrm{C} \rightarrow \mathrm{A}: \mathrm{T}$ transitions at $\mathrm{CpG}$ sites in the KSA is the lowest in the world. IARC mutation spectrum data on all breast cancer cases reported frequencies of $17.7 \%$ at the non-CpG sites and $21.3 \%$ at the $\mathrm{CpG}$ sites (21). This variation in the TP53 mutation pattern among different populations may be due to exposure to various environmental mutagens (23). The association between mutations and specific exogenous mutagens has been observed in the TP53 gene. The best example is the $\mathrm{CC} \rightarrow \mathrm{TT}$ tandem dipyrimidine transition associated with UV light and $\mathrm{G} \rightarrow \mathrm{T}$ transversions associated with benzo(a)pyrene (14). In the Saudi breast cancer patients, the most distinguishing feature of the TP53 mutation pattern was the excess of $\mathrm{G}: \mathrm{C} \rightarrow \mathrm{A}: \mathrm{T}$ transition at the non-CpG sites, which was rarely found at the $\mathrm{CpG}$ sites. The transition of cytosine to thymine at the $\mathrm{CpG}$ sites may result from spontaneous deamination of methylated cytosine (29). Therefore, the low frequency of this transition in the Saudi breast cancer patients is likely to be due to the low cytosine methylation at the $\mathrm{CpG}$ sites. On the other hand, the $\mathrm{G}: \mathrm{C} \rightarrow \mathrm{A}: \mathrm{T}$ transitions at the non-CpG sites is induced by various carcinogens, in particular oxidizing agents and alkylating agents such as $\mathrm{N}$-nitroso compounds (e.g., nitrosoamines and N-nitrosodimethylamine 'NDMA') (14). The carcinogenic effect of the $\mathrm{N}$-nitroso compounds on the mammary gland of laboratory animals is well established, suggesting that human mammary epithelial cells contain DNA adducts due to exposure to these chemicals (30,31). N-nitroso compounds (e.g., N-nitrosdimethylamines) are procarcinogenic agents that are bioactivated by enzymatic metabolism $(32,33)$. These agents lead to guanine alkylation generating $\mathrm{O}^{6}$-alkylguanine (e.g., $\mathrm{O}^{6}$-methylguanine), which typically results in $\mathrm{G}: \mathrm{C} \rightarrow \mathrm{A}: \mathrm{T}$ transitions (34). This adduct can be directly repaired by alkylguanine alkyltransferase enzymes (e.g. $\mathrm{O}^{6}$-methylguanine DNA methyl transferase enzymes) (35). This enzyme has been detected in breast tissue with large interindividual variations in activity (36). Zaidi et al demonstrated that the presence of estrogen increased the amount of $\mathrm{O}^{6}$-methylguanine in the DNA of breast xenografts (34). Therefore, high exposure to nitrosamines (or NDMA) with insufficient capacity for DNA repair or high levels of estrogen may lead to the accumulation of DNA damage and the formation of mutations that trigger cellular transformation and then breast carcinogenesis. These mutagens and the type of mutations they induce have been shown to play a role in the etiopathogenesis of oesophageal and gastric carcinomas (37-39).

Findings of our study showed that among the 33 patients with tumors harboring TP53 mutations, 24 (73\%) were young patients ( $<50$ years of age), while only $9(27 \%)$ were older patients ( $\geq 50$ years of age). Furthermore, TP53 mutations occurred more frequently in tumors from young patients with a prevalence of $34.8 \%$ than in the older patients with a prevalence of $27.3 \%$. However, this difference was not statistically significant $(\mathrm{p}=0.45)$. Studies have reported the presence of an association between TP53 mutations and the age of breast cancer onset (13). However, Nagai et al who reported on the Brazilian population, found no significant correlation between the age of breast cancer patients and p53 mutations (28).

In the present study, the frequency of p53 mutations in the Arab breast cancer patients was found to be among the highest in the world (40\%), with a high proportion of these mutations localized in exon 4 of the gene. Five out of these 12 mutations were identified for the first time. We also identified 2 novel deletions in exon 5. In addition, 16 mutations were identified for the first time in these breast cancer patients. A total of $70 \%$ of the patients harboring p 53 mutations in their tumors were younger than 50 years of age. Therefore, it can be concluded that the TP53 gene plays a signficant role in breast carcinogenesis and the early onset of the disease among Arab female individuals. 


\section{Acknowledgements}

We are very thankful to KACST for their financial help. We also thank the KFSH \& RC administration as well as the Training and Education and ORA offices for their continuous assistance. This study was performed under the RAC proposal \#2040037 and KACST \#LPG 10-9.

\section{References}

1. Parkin DM: International variation. Oncogene 23: 6329-6340, 2004.

2. Garfinkel L, Boring $\mathrm{CC}$ and Heath $\mathrm{CW}$ : Changing trends. An overview of breast cancer incidence and mortality. Cancer 74 222-227, 1994

3. Polyak K, Porter DA, Krop IE, Nasser S, Sgroi D, Kaelin CM, Marks JR and Riggins G: On the birth of breast cancer. Biochim Biophys Acta 1552: 1-13, 2001

4. Ezzat AA, Ibrahim EM, Raja MA, Al-Sobhi S, Rostom A, Stuart RK, al-Mulhim FA, al-Amri A, al-Muhanna FA and Ajarim D: Locally advanced breast cancer in Saudi Arabia: high frequency of stage III in a young population. Breast cancer in the eastern province of Saudi Arabia. Med Oncol 16: 95-103, 1999.

5. Neuhausen SL: Ethnic differences in cancer risk resulting from genetic variation. Cancer 86: 2575-2582, 1999.

6. Perera NM and Gui GP: Multi-ethnic differences in breast cancer: current concepts and future directions. Int J Cancer 106: 463-467, 2003

7. Polyak K: Molecular alterations in ductal carcinoma in situ of the breast. Curr Opin Oncol 14: 92-96, 2002.

8. Greenblatt MS, Bennett WP, Hollstein M and Harris CC: Mutations in the p53 tumor suppressor gene: clues to cancer etiology and molecular pathogenesis. Cancer Res 54: 4855-4878, 1994.

9. Bargonetti J and Manfredi JJ: Multiple roles of the tumor suppressor p53. Curr Opin Oncol 14: 86-91, 2002.

10. Soussi T, Legros Y, Lubin R, Ory K and Schlichtholz B: Multifactorial analysis of p53 alteration in human cancer: review. Int J Cancer 57: 1-9, 1994.

11. Olivier M, Langerod A, Carrieri P, Bergh J, Klaar S, Eyfjord J, Theillet C, Rodriguez C, Lidereau R, Bieche I, Varley J, Bignon Y, Uhrhammer N, Winqvist R, Jukkola-Vuorinen A, Niederacher D, Kato S, Ishioka C, Hainaut P and Borresen-Dale AL: The clinical value of somatic TP53 gene mutations in 1,794 patients with breast cancer. Clin Cancer Res 12: 1157-1167, 2006.

12. Hartmann A, Blaszyk H, McGovern RM, Schroeder JJ, Cunningham J, De Vries EM, Kovach JS and Sommer SS: p53 gene mutations inside and outside of exons 5-8: the pattern differ in breast and other cancers. Oncogene 10: 681-688, 1995.

13. Berns EM, Foekens JA, Vossen R, Look MP, Devilee P, HenzenLogmans SC, van Staveren IL, van Putten WL, Inganas M, Meijer-van Gelder ME, Cornelisse C, Claassen CJ, Portengen H, Bakker B and Klijn JG: Complete sequencing of TP53 predicts poor response to systemic therapy of advanced breast cancer. Cancer Res 60: 2155-2162, 2000.

14. Olivier M and Hainaut P: TP53 mutation patterns in breast cancers: searching for clues of environmental carcinogenesis. Semin Cancer Biol 11: 353-360, 2001.

15. Lowe SW, Ruley HE, Jacks T and Housman DE: p53-dependent apoptosis modulates the cytotoxicity of anticancer agents. Cell 74: 957-967, 1993

16. Borresen-Dale AL: TP53 and breast cancer. Hum Mutat 21: 292-300, 2003

17. Geisler S, Borresen-Dale AL, Johnsen H, Aas T, Geisler J, Akslen LA, Anker G and Lonning PE: TP53 gene mutations predict the response to neoadjuvant treatment with 5-fluorouracil and mitomycin in locally advanced breast cancer. Clin Cancer Res 9: 5582-5588, 2003

18. Langerod A, Zhao H, Borgan O, Nesland JM, Bukholm IR, Ikdahl T, Karesen R, Borresen-Dale AL and Jeffrey SS: TP53 mutation status and gene expression profiles are powerful prognostic markers of breast cancer. Breast Cancer Res 9: R30, 2007.

19. Hartmann A, Blaszyk H, Kovach JS and Sommer SS: The molecular epidemiology of p53 gene mutations in human breast cancer. Trends Genet 13: 27-33, 1997.
20. Pharoah PD, Day NE and Caldas C: Somatic mutations in the p53 gene and prognosis in breast cancer: a meta-analysis. Br J Cancer 80: 1968-1973, 1999.

21. Olivier M, Eeles R, Hollstein M, Khan MA, Harris CC and Hainaut P: The IARC TP53 database: new online mutation analysis and recommendations to users. Hum Mutat 19: 607-614, 2002.

22. Eachkoti R, Hussain I, Afroze D, Aejazaziz S, Jan M, Shah ZA, Das BC and Siddiqi MA: BRCA1 and TP53 mutation spectrum of breast carcinoma in an ethnic population of Kashmir, an emerging high-risk area. Cancer Lett 248: 308-320, 2007.

23. Hill KA and Sommer SS: p53 as a mutagen test in breast cancer. Environ Mol Mutagen 39: 216-227, 2002.

24. Hedau S, Jain N, Husain SA, Mandal AK, Ray G, Shahid M, Kant R, Gupta V, Shukla NK, Deo SS and Das BC: Novel germline mutations in breast cancer susceptibility genes BRCA1, BRCA 2 and $\mathrm{p} 53$ gene in breast cancer patients from India. Breast Cancer Res Treat 88: 177-186, 2004.

25. Faille A, De Cremoux P, Extra JM, Linares G, Espie M, Bourstyn E, De Rocquancourt A, Giacchetti S, Marty M and Calvo F: p53 mutations and overexpression in locally advanced breast cancers. Br J Cancer 69: 1145-1150, 1994.

26. Tsuda H, Iwaya K, Fukutomi T and Hirohashi S: p53 mutations and c-erbB-2 amplification in intraductal and invasive breast carcinomas of high histologic grade. Jpn J Cancer Res 84: 394-401, 1993.

27. Saitoh S, Cunningham J, De Vries EM, et al: p53 gene mutations in breast cancers in midwestern US women: null as well as missense-type mutations are associated with poor prognosis. Oncogene 9: 2869-2875, 1994.

28. Nagai MA, Schaer Barbosa H, Zago MA, Araujo Silva W Jr, Nishimoto IN, Salaorni S, Guerreiro Costa LN, Silva Araujo M, Caldas Oliveira AG, Mourao Neto M and Brentani MM: TP53 mutations in primary breast carcinomas from white and AfricanBrazilian patients. Int J Oncol 23: 189-196, 2003.

29. Kouidou S, Agidou T, Kyrkou A, Andreou A, Katopodi T, Georgiou E, Krikelis D, Dimitriadou A, Spanos P, Tsilikas C, Destouni $\mathrm{H}$ and Tzimagiorgis G: Non- $\mathrm{CpG}$ cytosine methylation of p53 exon 5 in non-small cell lung carcinoma. Lung Cancer 50: 299-307, 2005.

30. Reh BD, DeBord DG, Butler MA, Reid TM, Mueller C and Fajen JM: O(6)-methylguanine DNA adducts associated with occupational nitrosamine exposure. Carcinogenesis 21: 29-33, 2000.

31. Goldman R and Shields PG: Food mutagens. J Nutr 133 (Suppl 3): 965S-973S, 2003.

32. Schroeder JC, Conway K, Li Y, Mistry K, Bell DA and Taylor JA: p53 mutations in bladder cancer: evidence for exogenous versus endogenous risk factors. Cancer Res 63: 7530-7538, 2003.

33. Hecht SS and Hoffmann D: N-nitroso compounds and man: sources of exposure, endogenous formation and occurrence in body fluids. Eur J Cancer Prev 7: 165-166, 1998.

34. Zaidi SN, Laidlaw I, Howell A, Potten CS, Cooper DP and O'Connor PJ: Normal human breast xenografts activate N-nitrosodimethylamine: identification of potential target cells for an environmental nitrosamine. Br J Cancer 66: 79-83, 1992.

35. Scharer OD: Chemistry and biology of DNA repair. Angew Chem Int Ed Engl 42: 2946-2974, 2003.

36. Cao EH, Fan XJ, Yuan XH, Xin SM, Liu YY and Yu HT: Levels of $\mathrm{O}^{6}$-methylguanine acceptor protein in extracts of human breast tumor tissues. Cancer Biochem Biophys 12: 53-58, 1991.

37. Lozano JC, Nakazawa H, Cros MP, Cabral R and Yamasaki H: G-->A mutations in p53 and Ha-ras genes in esophageal papillomas induced by $\mathrm{N}$-nitrosomethylbenzylamine in two strains of rats. Mol Carcinog 9: 33-39, 1994.

38. Mir MM, Dar NA, Gochhait S, Zargar SA, Ahangar AG and Bamezai RN: p53 mutation profile of squamous cell carcinomas of the esophagus in Kashmir (India): a high-incidence area. Int J Cancer 116: 62-68, 2005.

39. Siddiqi M, Kumar R, Fazili Z, Spiegelhalder B and Preussmann R: Increased exposure to dietary amines and nitrate in a population at high risk of oesophageal and gastric cancer in Kashmir (India). Carcinogenesis 13: 1331-1335, 1992. 